\title{
RENTABILIDADE ECONÔMICA DO CULTIVO DO MARACUJAZEIRO-AMARELO SOB DIFERENTES PODAS DE FORMAÇÃO ${ }^{1}$
}

\author{
OSCAR MARIANO HAFLE², JOSÉ DARLAN RAMOS 3 , \\ SEBASTIÃO ELVIRO DE ARAÚJO NETO ${ }^{4}$, VANDER MENDONÇA ${ }^{5}$
}

RESUMO - O objetivo deste trabalho foi analisar a rentabilidade econômica do maracujazeiro-amarelo, sob diferentes formações da planta. O experimento foi conduzido em pomar comercial no Município de LavrasMG (21 $1^{\circ} 14^{\prime} \mathrm{S} ; 45^{\circ} 58^{\prime} \mathrm{W} ; 910 \mathrm{~m}$ de altitude), durante dois ciclos de produção (2006/2007). Os tratamentos constituíram na formação das plantas com diferente número de ramos terciários $(\mathrm{T} 1=40, \mathrm{~T} 2=30, \mathrm{~T} 3=24$, T4=20 e T5=14 por planta). O delineamento utilizado foi em blocos casualizados, com quatro repetições, sendo a parcela composta por três plantas. Os custos econômicos e operacionais médios foram maiores para os sistemas de podas mais drásticas (manutenção de 20 e 14 ramos por planta), por apresentarem maior custo de produção e menor produtividade. A receita líquida foi negativa para os sistemas de condução com menor quantidade de ramos terciários (T4 e T5). Os sistemas com podas menos drásticas apresentaram receita líquida positiva variando de $\mathrm{R} \$ 1.861,06 /$ ha no T3 a $\mathrm{R} \$ 3.895,74 /$ ha $(2006 / 2007)$ no T2. Nos tratamentos T1, T2 e T3, o resultado da situação econômica foi de lucro supernormal, indicando que a atividade está obtendo retornos maiores que as melhores alternativas possíveis de emprego do capital. Porém, nos tratamentos T4 e T5, os resultados foram de resíduos positivo e negativo, respectivamente, cobrindo apenas parte dos custos da lavoura, com a tendência do produtor de maracujá de buscar melhores alternativas de aplicação do seu capital, com abandono da atividade.

Termos para indexação: Passiflora edulis Sims f. flavicarpa Deg., poda, análise financeira.

\section{ECONOMIC RENTABILITY OF YELLOW PASSION FRUIT CROP UNDER DIFFERENT FORMATION PRUNINGS}

\begin{abstract}
The objective was to analyze the economic profitability of yellow passion fruit under different plant formations. The experiment was conducted in commercial orchard in the city of Lavras, MG $\left(21^{\circ} 14^{\prime} \mathrm{S}, 45^{\circ} 58^{\prime} \mathrm{W}, 910 \mathrm{~m}\right.$ altitude), for two production cycles (2006 and 2007). The treatments were the formation of plants with different number of tertiary branches $(\mathrm{T} 1=40, \mathrm{~T} 2=30, \mathrm{~T} 3=24, \mathrm{~T} 4=20$ and $\mathrm{T} 5=14$ per plant). The design was randomized blocks with four replications of three plants. The economic and operational costs were higher for more drastic pruning systems (20 and 14 branches per plant), which presented higher production cost and lower productivity. The net income was negative for systems of less tertiary branches (T4 and T5). The systems with less drastic pruning had positive net income ranging from $\mathrm{R} \$ 1,861.06 /$ ha in T3 to R \$3,895.74/ha (2006/2007) in T2. In T1, T2 and T3 the economic situation result was super normal profits, indicating that the activity is getting returns higher than the best alternatives for capital employment. However, in the treatments T4 and T5, the results were of positive and negative residues, respectively, covering only part of the farming costs, with the trend that the producer seeks better alternatives for its capital application, with the abandonment of the activity.
\end{abstract}

Index terms: Passiflora edulis Sims f. flavicarpa Deg., pruning, financial analysis.

\footnotetext{
1(Trabalho 199-09). Recebido em: 21-08-2009. Aceito para publicação en: 21-05-2010.

${ }^{2}$ Dr. Prof. no Instituto Federal de Educação, Ciência e Tecnologia da Paraíba, Campus de Sousa (IFPB-Sousa), Caixa Postal 49, CEP 58800-970, Sousa-PB. omhafle@hotmail.com. Autor correspondente.

${ }^{3}$ Dr. Prof. na Universidade Federal de Lavras, Caixa Postal 3037, CEP 37200-000, Lavras-MG. darlan@ufla.br

${ }^{4}$ Dr. Prof. na Universidade Federal do Acre, BR 364, km 04, CEP 69.915-900, Rio Branco-Acre. selviro2000@yahoo.com.br

${ }^{5}$ Dr. Prof. na Universidade Federal Rural do Semiárido (UFERSA), BR 110 - Km 47, Bairro Pres. Costa e Silva

CEP 59.625-900, Mossoró - RN, vanderm2000@hotmail.com
} 


\section{INTRODUÇÃO}

O cultivo de maracujazeiro é de grande importância para médias e pequenas propriedades rurais. O maracujá-amarelo (Passiflora edulis Sims. f. flavicarpa Deg.), também conhecido como maracujá-azedo, representa aproximadamente 95\% da produção nacional. Sua importância social está no fato de que a atividade propicia em torno de seis empregos por hectare, sendo dois diretos e quatro indiretos, estando diretamente associado à produção de base familiar (COSTA et al., 2005).

No Brasil, houve alta da produção e área plantada nos anos de 2007 e 2008, após terem sofrido queda nos anos de 2005 e 2006. Em 2008, a cultura ocupou a área de 44.363 ha, produzindo 615.196 t. A média nacional de produtividade é considerada baixa $(13,87 \mathrm{t} / \mathrm{ha})$, quando comparada às produtividades esperadas ao redor de $30.000 \mathrm{~kg} \mathrm{ha}^{-1}$ (Anuário da Agricultura Brasileira - AGRIANUAL, 2009).

Mesmo sendo uma cultura de retorno rápido do investimento, os baixos preços pagos pelo fruto, aliados aos altos custos de produção, têm levado obrigatoriamente a se fazer com frequência o diagnóstico do comportamento econômico-financeiro de cada ciclo da cultura, principalmente quando há aplicação de novas tecnologias, como a modificação na condução da planta.

A formação ou condução inicial da planta tem por finalidade proporcionar uma estrutura adequada de ramos, com uma distribuição equilibrada destes, havendo arejamento e iluminação convenientes (SOUSA, 2005). A forma de implantação e de condução da cultura afeta a produtividade e o custo de produção, sendo que, numa situação de baixo retorno do capital investido devido ao mercado (preço e custo), detalhes no cultivo são de fundamental importância para a permanência de investimentos na lavoura (ARAÚJO NETO et al., 2005; ARAÚJO NETO et al., 2008).

Além dos fatores de mercado, há de se considerar a produtividade e a longevidade dos pomares de maracujazeiro. Com o surgimento de novas áreas de cultivo e a expansão da cultura, observou-se o aparecimento de diversos problemas fitossanitários. Entre eles existe a "morte prematura" de causa ainda desconhecida e o "vírus do endurecimento dos frutos", uma das doenças mais importantes da cultura do maracujazeiro no Brasil (RONCATTO et al., 2004; NASCIMENTO et al., 2004). Uma alternativa para o agricultor seria eliminar o plantio após o segundo ano e implantar novamente a cultura, utilizando a mesma estrutura de sustentação e irrigação, ou, ainda, não fazer manutenção da cultura e colher o que a planta oferecer sem os devidos tratos culturais.

A análise econômica, comparando as diferentes formas de condução da planta, faz a conversão das variações produtivas em unidades monetárias, facilitando a decisão do produtor. Essa análise é composta de: custo de produção, análise econômica simplificada, receita líquida, taxa de retorno, ponto de nivelamento e ponto de resíduo (REIS, 2007; ARAÚJO NETO, 2004).

Fica difícil a decisão de se adotar ou não determinada prática de manejo cultural, a exemplo da poda de formação, pela escassez de trabalhos avaliando a produtividade e a eficiência econômica do sistema adotado. Por isso, o objetivo deste trabalho foi analisar a rentabilidade econômica da cultura do maracujazeiro-amarelo sob diferentes formações nas condições edafoclimáticas de Lavras-MG.

\section{MATERIAL E MÉTODOS}

$\mathrm{O}$ experimento foi instalado e conduzido entre os meses de setembro de 2005 e maio de 2007, em pomar comercial localizado no município de Lavras, sul do Estado de Minas Gerais. As coordenadas geográficas do local são: latitude de $21^{\circ}$ 14 ' S, longitude de $45^{\circ} 58^{\prime}$ 'W e altitude de $910 \mathrm{~m}$.

Foram utilizadas plantas de maracujazeiroamarelo, oriundas de sementes, implantadas no campo em covas, no espaçamento de $4 \mathrm{~m}$ entre plantas e 3 metros entre fileiras ( 833 plantas por hectare). Essas foram conduzidas sob sistema do tipo espaldeira vertical com um fio de arame, esticado horizontalmente a $180 \mathrm{~cm}$ do solo, sendo um ramo primário (caule), dois ramos secundários (no fio de arame) e crescimento livre dos ramos terciários (pendente). Foi utilizada a mesma estrutura de cultivo (espaldeira e irrigação) de um plantio anterior, eliminado após o terceiro ano de cultivo. As covas foram abertas na mesma linha de plantio, porém alternadamente às do plantio anterior, após a capina da linha em faixa de $2 \mathrm{~m}$, mantendo-se o restante da área apenas roçada.

$\mathrm{O}$ delineamento experimental adotado foi o de blocos casualizados, com 5 tratamentos e 4 repetições, com 3 plantas por parcela. Os tratamentos foram os diferentes números de ramos $(\mathrm{T} 1=40$, $\mathrm{T} 2=30, \mathrm{~T} 3=24, \mathrm{~T} 4=20$ e $\mathrm{T} 5=14$ por planta), mantidos durante a formação do pomar, no primeiro ciclo (ano 1) de cultivo. Esses foram conduzidos na forma de cortina, com poda aos $20 \mathrm{~cm}$ do solo.

Os tratos culturais adotados no pomar foram os comumente usados na região para a cultura. A polinização manual foi realizada somente em períodos de maior intensidade de floração. As ervas daninhas 
foram controladas com capina manual ao redor da planta, aplicação de herbicida no restante da linha de plantio e capina mecânica nas entrelinhas de plantio. Após o final do primeiro ciclo produtivo do pomar (18-08-2006), foi realizada poda manual de renovação, deixando os ramos terciários (cortina) com média de $80 \mathrm{~cm}$, medidos a partir da sua base (inserção no ramo secundário).

Durante o período experimental, ocorreu ataque de pragas e doenças que foram controladas com o uso dos inseticidas Cartap BR e Lebaycid EC e dos fungicidas Folicur CE e Thiobel. A necessidade hídrica das plantas foi suprida através da irrigação com sistema de gotejamento, aplicando lâmina de água de $6 \mathrm{~mm}$ diários de forma suplementar, nos períodos de estiagem. As colheitas foram realizadas nos períodos de março a julho/06, dezembro/06 a maio/07, com intervalo médio de três dias, coletando os frutos comerciais caídos ao solo, procedendo-se a contagem e a pesagem dos mesmos.

A análise econômica consistiu em: custo de produção, análise econômica simplificada, receita líquida (RL), índice de rentabilidade (IR), ponto de nivelamento $\left(\mathrm{q}_{\mathrm{n}}\right)$ e ponto de resíduo $\left(\mathrm{q}_{\mathrm{r}}\right)$ (REIS, 2007; ARAÚJO NETO, 2004).

O custo total é composto de custo fixo (equipamentos, espaldeira e custo alternativo) e variável (insumos, mão de obra, despesas administrativas, custo alternativo e aluguel da terra). A espaldeira entrou como custo fixo, por ser utilizada em três cultivos de 2,5 anos, assim o custo para este experimento foi de $\mathrm{R} \$ 1.000,00$, sendo o restante dos $\mathrm{R} \$ 2.000,00$ distribuídos em futuros plantios. Os preços dos produtos e serviços foram levantados na região da localização do experimento, nos anos de 2006 e 2007.

Considerou-se, para a implantação da espaldeira, o coveamento e a limpeza da área com métodos manuais, situação comumente encontrada na região. O valor da diária de trabalho foi determinado tomando como base o valor médio pago na região, que foi de $\mathrm{R} \$ 15,00 / \mathrm{HD}$ (homem-dia) em 2006 e R \$ 17,00/HD em 2007.

No Município de Lavras, os preços médios de comercialização do maracujá para mesa, em 2005, foi de R \$1,00/kg, e em $2006 \mathrm{R} \$ 1,10 / \mathrm{kg}$, o preço de venda de maracujá para indústria foi de $\mathrm{R} \$ 0,50$, que não variou durante os três anos; assim, considerando a comercialização de metade da produção para indústria e a outra para mesa, adotamos a média de R\$ $0,80 / \mathrm{kg}$, que denominamos de receita média (RMe). Apesar de a seleção de frutos maiores (mesa) ser de 10\% a 30\% (OLIVEIRA; RUGGIERO, 1998), estes podem ser comercializados por até $150 \%$ acima do valor dos frutos menores (indústria) (MELETTI;
MAIA, 1999). Adotou-se o percentual de 50\% para cada segmento (mesa e indústria) (ARAÚJO NETO, 2004), pois as condições de mercado, logística e perfil do agricultor é que definem este percentual.

Para efeito da análise do custo alternativo dos recursos alocados na produção, considerou-se a taxa de juros de $12 \%$ a.a., baseada na taxa Selic, mais o aluguel da terra. $\mathrm{O}$ aluguel foi considerado como sendo de R \$252,00/ha/ano, correspondendo a um litro de leite $\mathrm{ha}^{-1} \mathrm{dia}^{-1}$, no valor de $\mathrm{R} \$ 0,70$, ou seja, $\mathrm{R} \$ 21,00 \mathrm{ha}^{-1} \mathrm{mês}^{-1}$. Essa metodologia foi proposta por Silva et al. (2003) para a região sul-mineira.

Os custos operacionais fixos e variáveis (CopF, CopV) constituem-se dos custos com os insumos e serviços efetivamente empregados na atividade produtiva, excluídos os custos alternativos. Os custos operacionais médios (CopFMe e CopVMe) constituem-se nos valores do quociente dos custos fixos ou variáveis totais pela produtividade.

A renda líquida $(R L)$ é a diferença entre o rendimento bruto e o custo total da lavoura (CT). O índice de rentabilidade (IR) foi calculado mediante a razão entre a receita bruta e o custo operacional total (CopT). Os pontos de nivelamento $\left(\mathrm{q}_{\mathrm{n}}\right)$ e de resíduo $\left(\mathrm{q}_{\mathrm{r}}\right)$ foram obtidos a partir das fórmulas: $\left[\mathrm{q}_{\mathrm{n}}=\mathrm{CT} /\right.$ preço $]$ e $\left[\mathrm{q}_{\mathrm{r}}=\mathrm{CopT} /\right.$ preço $](\mathrm{kg}$ por ha em 2 safras), em que: $\mathrm{CT}=$ custo total, e CopT $=$ custo operacional total. Os coeficientes técnicos referentes às operações de implantação e condução da cultura foram determinados através do acompanhamento dos experimentos.

Os dados de produção foram submetidos à análise de variância, por meio do teste $\mathrm{F}$, e as médias, comparadas pelo teste de Scott-Knott, ambos a $5 \%$ de probabilidade, utilizando o aplicativo SISVAR (FERREIRA, 2000). Confirmada diferença estatística significativa, foi realizada análise econômica, como premissa de que também apresenta significância estatística, mas não testada, por falta de homogeneidade dos dados, causados pelos índices econômicos e não por efeito do ambiente como na produtividade.

\section{RESULTADOS E DISCUSSÃO}

\section{Custo de produção}

Ao analisar a Tabela 1 , referente ao percentual de participação dos componentes do custo total de produção, verifica-se que o custo variável representa $86,3 \%$, e o custo fixo, $13,7 \%$ do custo total, para a média geral dos tratamentos, com pouca variação entre eles. Nos custos variáveis, merecem destaque os insumos e a mão de obra, compondo, juntos, $73,9 \%$ destes. 
Os custos fixos estão representados principalmente pelos equipamentos e espaldeira (Tabela 1). Na região de Lavras, os produtores comercializam as frutas para a indústria, comerciantes de hortifrutis e diretamente ao consumidor. Por serem os frutos comercializados logo após a colheita e sem refrigeração, a atividade não exige altos investimentos em benfeitorias, como casa de embalagem e locais de armazenamento dos frutos.

Entre os tratamentos, o custo total acumulado variou de $\mathrm{R} \$ 20.299,16 /$ ha no tratamento com maior número de ramos terciários a $\mathrm{R} \$$ $20.749,40 /$ ha, no tratamento com menor número de ramos terciários (Tabela 2). Nas safras de 2006 e 2007, o custo total médio de produção variou, respectivamente, de $\mathrm{R} \$ 11.295,65$ a $\mathrm{R} \$ 9.224,82$ / ha para as duas safras, respectivamente.

A maior remuneração da lavoura (lucro líquido) ocorreu na segunda safra e no tratamento com a manutenção de trinta ramos terciários na poda de formação (Tabela 2). No primeiro ano, em todos os tratamentos, o rendimento bruto não cobriu o custo total de produção; porém, se for considerado o somatório das duas safras, apenas os tratamentos T1, T2 e T3 apresentaram desempenho positivo, sendo o T2 o de melhor retorno econômico. Nas somas dos anos I e II, obteve-se lucro líquido de R \$ $1.851,15, \mathrm{R} \$ 3.171,52$ e $\mathrm{R} \$ 1.247,09$ por hectare, respectivamente, para os tratamentos T1, T2 e T3, tendo os demais tratamentos resultados negativos.

A eliminação de parte dos ramos terciários (poda leve) mostrou-se benéfica para o maracujazeiro, aumentando a produtividade com esta prática. Isso reforça as conclusões de Cavichioli et al. (2006), de que a espécie é sensível ao sombreamento, sendo este prejudicial ao desenvolvimento normal, afetando o crescimento vegetativo, o florescimento, a frutificação e a produtividade da planta.

\section{Análise econômica simplificada}

No geral, os custos médios $(\mathrm{R} \$ / \mathrm{kg})$ da produção do maracujazeiro aumentam com a intensificação da poda (Tabela 3), porém o tratamento em que foram deixados 30 ramos terciários (T2), apresentou os menores valores devido ao aumento da produtividade. Por outro lado, o T4 e o T5 apresentam os maiores custos operacionais, devido às produções mais baixas e aos maiores custos de produção.

De acordo com Reis (2007), a situação econômica dos tratamentos T1, T2 e T3 são de lucro supernormal (Tabela 3). Essa situação ocorre quando a receita média ou o preço médio $(\mathrm{R} \$ 0,80 / \mathrm{kg})$ for maior que o custo total médio (CTMe), indicando que a atividade está obtendo retornos maiores que as melhores alternativas possíveis de emprego do capital. Para o tratamento T4, houve resíduo positivo, isto é, o rendimento paga todos os custos operacionais aplicados na atividade (CopTMe) e parte do custo alternativo. No tratamento T5, a situação foi de resíduo negativo, em que a atividade não consegue pagar sequer os custos operacionais.

A principal causa dessa situação foi que os tratamentos com maior número de ramos terciários (T1, T2 e T3) apresentaram as maiores produtividades por área. Para os demais tratamentos, como a rentabilidade é baixa, pode haver desestímulo em continuar com a atividade, levando o agricultor a buscar melhores alternativas de aplicação do capital.

Considerando os dois anos de produção com os frutos comercializados em sistema misto (indústria e varejo), a receita líquida variou de $\mathrm{R} \$$ $4.570,50 /$ ha no tratamento T5 a R $\$ 3.895,74 /$ ha no tratamento T2 (Tabela 4), reflexos do aumento na produtividade, principalmente nos tratamentos $\mathrm{T} 1$ e T2 (Tabela 3). O índice de retorno foi $15,48 \%$, $16,44 \%, 15 \%$ e $13,44 \%$ para os tratamentos $\mathrm{T} 1, \mathrm{~T} 2, \mathrm{~T} 3$ e T4, respectivamente, ficando acima da taxa do custo alternativo $(12 \%+$ aluguel da terra). No tratamento T5, por apresentar resíduo negativo, não houve retorno do capital investido, e, sim, perda de $13,2 \%$. Para uma receita média de $\mathrm{R} \$ 0,80 / \mathrm{kg}$, a quantidade de frutos produzidos para cobrir todos os custos de produção $\left(\mathrm{q}_{\mathrm{n}}\right)$ foi maior que a produtividade $\left(\mathrm{kg} \mathrm{ha}^{-1}\right)$ no tratamento T5.

Pires e São José (1994) afirmam que a cultura do maracujá sempre foi caracterizada por grandes oscilações de preços pagos aos fruticultores que, por sua vez, ajustam sua produção de acordo com essas variações, o que reflete no total da área plantada. Além disso, o preço, os custos de produção e a rentabilidade da lavoura variam de região para região, em função do nível de conhecimento e infraestrutura do fruticultor, destino da produção (indústria e ou fruta fresca), condições edafoclimáticas, ocorrência de pragas e doenças, distância do mercado consumidor, dentre outros.

A receita líquida de $\mathrm{R} \$ 1.947,87 / \mathrm{ha} /$ ano pode parecer baixo, mas comparado ao rendimento de um hectare de soja ( $\mathrm{R} \$ 200,00)$, é alto. Além disso, este valor é considerado lucro líquido, e caso a produção tenha mão de obra familiar, os custos computados com este item fica na propriedade para a manutenção da família.

Araújo Neto (2004) afirma que a rentabilidade econômica da cultura depende muito do preço do maracujá, principalmente em anos em que a produtividade é baixa, causada ora por veranicos 
antecedendo a emissão floral ora por excesso de precipitação pluviométrica durante o florescimento. O preço de venda tem-se mantido constante e baixo nos últimos anos, contribuindo para o declínio da produção de maracujá no Brasil (MEIRELES, 2006). Os preços pagos pela indústria de suco estão próximos ao limite inferior da média histórica de US $\$ 0,18$ a US\$0,25 o quilograma da fruta (GUEDES; VILELA, 1999). No entanto, nas CEASAS do DF, SP e BH, o maracujá in natura é mais valorizado, com preços que, em 2007 , variaram de $\mathrm{R} \$ 0,71 / \mathrm{kg}$ a $\mathrm{R} \$ 2,75 / \mathrm{kg}$, (AGRIANUAL, 2008).

A manutenção de preços baixos não seria grande problema se os custos de produção também congelassem baixos, mas, na prática, os custos sobem anualmente, principalmente dos insumos industrializados e importados, como os fertilizantes e defensivos agrícolas. Os preços dos fertilizantes químicos no Brasil crescem 9,9\% a.a (1994 a 2007) e com tendência de alta até 2018 (SAAD; PAULA, 2008).

TABELA 1 - Porcentagem dos custos fixos e variáveis da produção de maracujá nas diferentes formações, provenientes das duas safras acumuladas (2006 e 2007).

\begin{tabular}{lcccccc}
\hline \multirow{2}{*}{ Custos Fixos e Variáveis* } & \multicolumn{6}{c}{ Porcentagem do custo total } \\
& T1 & T2 & T3 & T4 & T5 & Média \\
\hline Custos Fixos & 7,4 & 7,4 & 7,3 & 7,3 & 7,2 & $\mathbf{7 , 3}$ \\
Equipamentos & 4,9 & 4,9 & 4,9 & 4,9 & 4,8 & $\mathbf{4 , 9}$ \\
Espaldeira & 1,5 & 1,5 & 1,5 & 1,5 & 1,4 & $\mathbf{1 , 5}$ \\
Custo alternativo & 13,8 & 13,8 & 13,7 & 13,6 & 13,5 & $\mathbf{1 3 , 7}$ \\
\hline CFT & & & & & & \\
Custos variáveis & 28,2 & 28,1 & 27,9 & 27,8 & 27,6 & $\mathbf{2 7 , 9}$ \\
Insumos & 45,6 & 45,8 & 46,0 & 46,3 & 46,5 & $\mathbf{4 6 , 0}$ \\
Mão de obra & 1,0 & 1,0 & 1,0 & 1,0 & 1,0 & $\mathbf{1 , 0}$ \\
Despesas administrativas & 11,4 & 11,4 & 11,4 & 11,4 & 11,4 & $\mathbf{1 1 , 4}$ \\
Custo alternativo + terra & 86,2 & 86,2 & 86,3 & 86,4 & 86,5 & $\mathbf{8 6 , 3}$ \\
\hline CVT & 100,0 & 100,0 & 100,0 & 100,0 & 100,0 & $\mathbf{1 0 0 , 0}$ \\
\hline CT (CFT+CVT) & & & & & &
\end{tabular}

* CFT = custo fixo total; $\mathbf{C V T}=$ custo variável total e $\mathbf{C T}=$ custo total.

TABELA 2 - Estimativa de custo e rendimento $(\mathrm{R} \$ /$ ha $)$ da cultura do maracujazeiro nas diferentes formações da planta, em duas safras (2006 e 2007).

\begin{tabular}{|c|c|c|c|c|c|c|}
\hline \multirow{2}{*}{ Custos Fixos e Variáveis" } & \multicolumn{6}{|c|}{ Tratamentos } \\
\hline \multirow{2}{*}{\multicolumn{7}{|c|}{$\overline{\text { Ano I }}$}} \\
\hline & & & & & & \\
\hline Equipam & 0 & $1.500,00$ & $1.500,00$ & $1.500,00$ & $.500,00$ & $.500,00$ \\
\hline & & & $1.000,00$ & 1.000 & & 0,00 \\
\hline & & 2.99 & $2.993,40$ & $2.993,40$ & & $2.993,40$ \\
\hline a & & & $4.240,00$ & $4.315,00$ & & $4.240,00$ \\
\hline esp & & & 100,00 & 100,00 & & 100,00 \\
\hline ustc & & & $1.462,25$ & $1.471,25$ & & $1.462,25$ \\
\hline ustat & 5 & 11.21 & $11.295,651$ & $11.379,65$ & 11.4 & $11.295,65$ \\
\hline & & 13.6 & $11.434,62$ & $9.174,61$ & & $10.975,38$ \\
\hline & & 0,75 & 0,75 & 0,75 & 0,75 & 0,75 \\
\hline Sha & 08,97 & 229,66 & $8.575,97$ & $6.880,96$ & & 31,54 \\
\hline Lucro lí & & & $-2.719,68$ & & & \\
\hline \multicolumn{7}{|l|}{ Ano II } \\
\hline & & & $2.723,85$ & $2.723,85$ & & 2. \\
\hline & & & $5.191,00$ & $5.208,00$ & 5.24 & $5.187,60$ \\
\hline & & & 100,00 & 100,00 & & 100,00 \\
\hline & & $1.209,70$ & $1.213,78$ & $1.215,82$ & $1.219,90$ & $1.213,37$ \\
\hline & & & $9.228,63$ & $9.247,67$ & 9.2 & \\
\hline & 15. & $16.680,08$ & $16.494,25$ & $15.940,33$ & $12.754,67$ & $15.434,20$ \\
\hline & & & 0,80 & 0,80 & 0,80 & 0,80 \\
\hline & 4 & $13.344,06$ & $13.195,401$ & $12.752,27$ & $10.203,73$ & $12.347,36$ \\
\hline & $3.069,83$ & & $3.966,77$ & $3.504,59$ & 917,98 & $3.122,54$ \\
\hline Total acumulado & $20.299,16$ & $20.402,20$ & $20.524,28$ & $0.627,32$ & $20.749,40$ & $20.520,47$ \\
\hline
\end{tabular}


TABELA 3 - Custos econômicos e operacionais médios da produção do maracujazeiro nas diferentes formações da planta (2006 e 2007).

\begin{tabular}{|c|c|c|c|c|c|c|c|c|}
\hline \multirow{2}{*}{ Tratamentos } & $\mathbf{C F}$ & $\mathrm{CV}$ & CT & CopF & CopV & CopT & \multirow{2}{*}{$\begin{array}{l}\text { Produtividade } \\
\text { (kg/ha)* }\end{array}$} & \multirow{2}{*}{$\begin{array}{c}\text { Situação } \\
\text { Econômica }\end{array}$} \\
\hline & \multicolumn{6}{|c|}{ (R\$/kg) } & & \\
\hline $\mathrm{T} 1$ & 0,10 & 0,61 & 0,71 & 0,09 & 0,53 & 0,62 & $28.514 \mathrm{a}$ & LSN \\
\hline $\mathrm{T} 2$ & 0,09 & 0,58 & 0,67 & 0,08 & 0,50 & 0,59 & $30.320 \mathrm{a}$ & LSN \\
\hline $\mathrm{T} 3$ & 0,10 & 0,63 & 0,73 & 0,09 & 0,55 & 0,64 & $27.929 a$ & LSN \\
\hline $\mathrm{T} 4$ & 0,11 & 0,71 & 0,82 & 0,10 & 0,61 & 0,71 & $25.115 b$ & $\mathrm{RP}$ \\
\hline $\mathrm{T} 5$ & 0,14 & 0,89 & 1,03 & 0,12 & 0,77 & 0,89 & $20.171 \mathrm{c}$ & $\mathrm{RN}$ \\
\hline Média & 0,11 & 0,68 & 0,79 & 0,10 & 0,59 & 0,69 & 26.410 & \\
\hline
\end{tabular}

* médias seguidas de letras distintas na coluna diferem significativamente entre si, pelo teste de Scott-Knott $(\mathrm{P}<0,05)$.

CF - custo fixo médio; $\mathrm{CV}$ - custo variável médio; CT - custo total médio; CopF - custo operacional fixo médio; CopV - custo operacional variável médio; CopT - custo operacional total médio; LSN - Lucro supernormal; RP - Resíduo positivo; RN - Resíduo negativo

TABELA 4 - Receita líquida (RL), índice de rentabilidade (IR), ponto de nivelamento (qn) e de resíduo (qr), em 2 safras, nas diferentes formações da planta (anos de 2006 e 2007)

\begin{tabular}{llccc}
\hline Tratamentos & \multicolumn{1}{c}{$\mathbf{R L}$} & $\mathbf{I R}$ & $\begin{array}{c}\mathbf{q n} \\
\left(\mathrm{kg} \mathrm{ha}^{1}\right)\end{array}$ & $\begin{array}{c}\mathbf{q r} \\
\left(\mathrm{kg} \mathrm{ha}^{-1}\right)\end{array}$ \\
\hline T1 & $2.553,98$ & 1,29 & 21.821 & 18.934 \\
T2 & $3.895,74$ & 1,37 & 21.950 & 19.049 \\
T3 & $1.861,06$ & 1,25 & 22.103 & 19.185 \\
T4 & $-493,13$ & 1,12 & 22.231 & 19.300 \\
T5 & $-4.570,50$ & 0,89 & 22.384 & 19.437 \\
\hline Média & 649,43 & 1,19 & 22.097 & 19.181 \\
\hline
\end{tabular}

\section{CONCLUSÕES}

Nas condições em que o presente experimento foi realizado, é possível concluir que o custo total de produção aumenta, e a produtividade diminui com a intensificação da poda, ou seja, não é indicada a redução do número de ramos terciários na poda de formação.

\section{AGRADECIMENTOS}

À Fundação de Amparo à Pesquisa do Estado Minas Gerais (FAPEMIG) e à Coordenação de Aperfeiçoamento de Pessoal de Nível Superior (CAPES), pelo apoio financeiro ao projeto e concessão de bolsa de estudo.

\section{REFERÊNCIAS}

AGRIANUAL: Anuário da Agricultura Brasileira. Produção de frutas no Brasil. São Paulo: FNP Consultoria, 2008.

AGRIANUAL: Anuário da Agricultura Brasileira. Produção de frutas no Brasil. São Paulo: FNP Consultoria, 2009.

ARAÚJO NETO, S. E. de. Produção, qualidade e rentabilidade do maracujazeiro-amarelo em diferentes densidades de plantio. 2004. $72 \mathrm{f}$. Tese (Doutorado em Agronomia - Fitotecnia) - Universidade Federal de Lavras, Lavras, 2004.

ARAÚJO NETO, S. E. de; FERREIRA, R. L. F.; PONTES, F. S. T.; NEGREIROS, J. R. da S. Rentabilidade econômica do maracujazeiro-amarelo plantado em covas e em plantio direto sob manejo orgânico. Revista Brasileira de Fruticultura, Jaboticabal, v.30, p. 940-945, 2008. 
ARAÚJO NETO, S. E. de; RAMOS, J. D.; ANDRADE JÚNIOR, V. C. de; RUFINI, J. C. M.; MENDONÇA, V.; OLIVEIRA, T. K. de. Adensamento, desbaste e análise econômica na produção do maracujazeiro-amarelo. Revista Brasileira de Fruticultura, Jaboticabal, v. 27, n.3, p. 394-398 dez. 2005.

CAVICHIOLI, J. C. de; RUGGIERO, C.; VOLPE, A.; PAULO, E. M.; FAGUNDES, J. L.; KASAI, F. S. Florescimento e frutificação do maracujazeiroamarelo submetido à iluminação artificial, irrigação e sombreamento. Revista Brasileira de Fruticultura, Jaboticabal, v. 28, n.1, p. 92-96, 2006.

COSTA, A. de F. S.; ALVES, F. de L.; COSTA, A. N. de. Plantio, formação e manejo da cultura do maracujá. In: COSTA, A. de F. S.; COSTA, A. N. de (Ed.). Tecnologias para a produção de maracujá. Vitória: INCAPER, 2005. p. 23-53.

FERREIRA, D. F. SISVAR: sistema de análise de variância para dados balanceados, versão 4.0. Lavras: DEX/UFLA, 2000. Software estatístico.

GUEDES, L. de O; VILELA, P. S. O mercado do maracujá. Belo Horizonte: FAEMIG/Infoagro, 1999. 16 p.

MEIRELLES, M. C. Maracujá-maravilha. Frutas \& derivados, São Paulo, v. 1, n. 4, p.31-33, dez. 2006.

MELETTI, L. M. M.; MAIA, M. L. Maracujá: produção e comercialização. Campinas: IAC, 1999. 64 p. (Boletín Técnico, 181).

NASCIMENTO, A. V. S.; SOUZA, A. R. R.; ALFENAS, P. F.; ANDRADE, G. P. I.; CARVALHO, M. G.; PIO-RIBEIRO, G.; ZERBINI, F. M. Análise filogenética de potyvírus causando endurecimento dos frutos do maracujazeiro no nordeste do Brasil. Fitopatologia Brasileira, Brasília, v. 29, n. 4, p. 378-383, 2004.
OLIVEIRA, J. C.; RUGGIERO, C. Aspecto sobre o melhoramento do maracujazeiro-amarelo. In: SIMPÓSIO BRASILEIRO SOBRE A CULTURA DO MARACUJAZEIRO, 5., 1998, Jaboticabal. Anais... Jaboticabal: Funep, 1998. p. 291-310.

PIRES, M. de M.; SÃO JOSÉ, A. R. Custo de produção e rentabilidade da cultura do maracujazeiro. In: SÃO JOSÉ, A. R. (Ed.). Maracujá: produção e mercado. Vitória da Conquista: UESB, 1994. p. 223-233.

REIS, R. P. Fundamentos de economia aplicada. Lavras: UFLA/FAEPE, 2007. 95 p. Texto Acadêmico.

RONCATTO, G.; OLIVEIRA, J. C. de; RUGGIERO, C.; NOGUEIRA FILHO, G. C.; CENTURION, A. P. da C.; FERREIRA, F. R. Comportamento de maracujazeiros (passiflora spp.) quanto à morte prematura. Revista Brasileira de Fruticultura, Jaboticabal, v. 26, n. 3, p. 552-554, dez. 2004.

SAAB, A. A.; PAULA, R. de A. O mercado de fertilizantes no Brasil : diagnósticos e propostas de políticas. Revista de Política Agrícola, Brasília, v.17, n. 2, p. 5-24, 2008.

SILVA, A. L. da; FARIA, M. A. de; REIS, R. P. Viabilidade técnico-econômica do uso do sistema de irrigação por gotejamento na cultura do cafeeiro.

Revista Brasileira de Engenharia Agrícola e Ambiental, Campina Grande, v. 7, n. 1, p. 37-44, 2003.

SOUSA, J.S. I. de. Poda das plantas frutíferas. São Paulo: Nobel, 2005. 191 p. 